\title{
Anti-inflammatory and Immunomodulatory Effect of an Extract of Coccidioides posadasii in Experimental Arthritis
}

\author{
Ana Carolina Matias Dinelly Pinto - Rossana de Aguiar Cordeiro • \\ José Julio Costa Sidrim • Ana Karine Rocha de Melo Leite • Ana Caroline Rocha de Melo Leite • \\ Virgínia Cláudia Carneiro Girão • Raimunda Sâmia Nogueira Brilhante • \\ Marcos Fábio Gadelha Rocha · Fernando de Queiroz Cunha - Francisco Airton Castro Rocha
}

Received: 3 September 2012/ Accepted: 21 January 2013/Published online: 5 February 2013

(C) Springer Science+Business Media Dordrecht 2013

\begin{abstract}
Trying to surpass host defenses, fungal infections alter the immune response. Components from nonpathogenic fungi present therapeutic anti-inflammatory and immunomodulating activities. This study reveals that proteins present in a Coccidioides posadasii extract provide anti-inflammatory benefit in experimental arthritis. Zymosan was given intra-articularly to rats and mice, and groups were pretreated with C. posadasii extract either per os or intraperitoneally. Controls received the vehicle. Acute hypernociception was evaluated using articular incapacitation and von Frey methods. Cell influx and cytokine levels were assessed in joint exudates. Joint damage was evaluated by histopathology and determination of glycosaminoglycan
\end{abstract}

A. C. M. D. Pinto - A. K. R. de Melo Leite ·

A. C. R. de Melo Leite - F. A. C. Rocha $(\bowtie)$

Department of Internal Medicine, Faculty of Medicine,

Federal University of Ceará, Rua Doutor José Lourenço

1930, Fortaleza, CE 60115-281, Brazil

e-mail: arocha@ufc.br

R. de Aguiar Cordeiro - J. J. C. Sidrim .

R. S. N. Brilhante - M. F. G. Rocha

Specialized Medical Mycology Center, Federal University

of Ceará, Fortaleza, CE, Brazil

V. C. C. Girão

Department of Morphology, Faculty of Medicine,

Federal University of Ceará, Fortaleza, CE, Brazil

F. de Queiroz Cunha

Department of Pharmacology, Faculty of Medicine,

University of São Paulo, Ribeirão Preto, SP, Brazil content of the cartilage. Synovia was evaluated for cell death and inducible nitric oxide synthase (iNOS) expression using TUNEL and immunohistochemistry, respectively. Pretreatment with $C$. posadasii extract significantly inhibited acute and chronic cell influx, hypernociception, and provoked reduction of glycosaminoglycan loss while reducing chronic synovitis, cell death, and iNOS expression. Reduction/alkylation of C. posadasii extract abrogated these effects. C. posadasii administration did not alter TNF- $\alpha$, IL-1 $\beta$, IL-17, and $\gamma$-interferon levels, whereas IL-10 levels were significantly reduced. Data reveal that a $C$. posadasii extract reduces iNOS expression that is associated with inhibition of synovial apoptosis and decrease in IL-10 levels released into zymosan-inflamed joints. Characterization of active components excluded charged carbohydrates while pointing to a protein as responsible for these effects. In summary, systemic administration of components from a pathogenic fungus provides anti-inflammatory effects, being species-independent and orally active. Besides adding to understand host response against fungi, the results may lead to therapeutic implications.

Keywords Coccidioides - Cytokines ·

Interleukin-10 $\cdot$ Nitric oxide $\cdot$ Fungus $\cdot$ Apoptosis

\section{Introduction}

Several studies have shown the anti-inflammatory and immunomodulating potential of fungal components. 
Polysaccharides, proteins, lipids, as well as secondary metabolites, such as triterpenes and phenols, have been described as molecules with immunomodulatory properties [1]. While displaying diverse structure, most fungal polysaccharides belong to $\beta$-glucans, which can be chemically modified in order to improve their biological potency. Though the exact mechanism of action of bioactive fungal components is unknown, a common pathway involves the activation of T-lymphocytes and macrophages, thus altering the cytokine repertoire released in the inflammatory response [2].

Differences in the prevalence of allergic and autoimmune diseases between highly industrialized countries and underdeveloped nations have been associated with a lower prevalence of infections [3]. Less exposure to house dust, high ingestion of industrialized food, diminished breast-feeding, and increased vaccination would decrease stimulation to "real-life" germs [4]. In keeping with this assumption, we have demonstrated that the administration of a nematode (Ascaris suum) extract was protective in arthritis models, provoking a decrease in the hypernociceptive response, cell migration, structural damage, and histological changes. These effects were coupled to an alteration in the release of cytokines into the joint exudates [5].

Attempts to demonstrate anti-inflammatory activity of fungi constituents or released products usually focus on nonpathogenic species. However, immunomodulation is also a strategy employed by pathogens to escape host defenses. The highly virulent fungi Coccidioides immitis/C. posadasii are the etiological agents of coccidioidomycosis, a severe disease that occurs in both humans and animals. Coccidioides species secrete an immunodominant antigen which is able to modulate host immunity in a Th2-biased manner [6]. However, Coccidioides can also secrete endosporulation antigens that stimulate or suppress cell-mediated immunity, depending on the antigen preparation method [7].

Our group is based in Ceará state (northeast of Brazil), and we have identified and characterized a C. posadasii strain isolated both from the bronchoalveolar lavage of affected patients and from the soil. In our region, the unprotected practice of armadillo (Dasypus novemcinctus and Euphractus sexcinctus) hunting exposes both humans and dogs to large amounts of dispersed Coccidioides spp. arthroconidia [8].

Zymosan is derived from Saccharomyces cerevisae. When injected into joints, zymosan promotes a severe and chronic arthritis that resembles rheumatoid arthritis $[9,10]$. Coupling to Toll-like receptors, Dectin-1 receptors and also mannose-binding lectins are involved in zymosan inflammation [11], thus opening the possibility of studying both innate and adaptive in vivo immune mechanisms in this arthritis model.

As said above, components from pathogenic fungi and/or their released products may provoke immunomodulatory changes as they encounter the host immune system. The objective of the present study was to investigate whether the systemic administration of an extract from our $C$. posadasii strain modifies the inflammatory response induced by injection of zymosan into rat and mouse joints.

\section{Materials and Methods}

Animals

All animal procedures and experimental protocols were approved by the local ethics committee on animal experimentation at the Faculty of Medicine of the Federal University of Ceará, Brazil (protocol number-90/07). All efforts were made to minimize animal suffering and the number of animals used. The animals were housed in temperature-controlled rooms with 12-h light/dark cycles and free access to water and food. Surgical procedure and animal treatments were conducted in accordance with the Guide for the Care and Use of Laboratory Animals (National Institutes of Health Publication).

Induction of the Zymosan Arthritis (ZYA)

Male Wistar rats (180-200 g) or Swiss mice (25-30 g) ( $n=6$ per group) from our own animal facilities were used throughout the experiments. Rats or mice received an intra-articular (i.a.) injection of either $1 \mathrm{mg}(0.05 \mathrm{ml}$ total volume $)$ or $0.1 \mathrm{mg}(0.025 \mathrm{ml}$ total volume) zymosan (Sigma, St. Louis, MO, USA), respectively, dissolved in sterile saline, into their right knee joints. Control groups received only saline i.a. [5].

\section{Evaluation of Joint Hypernociception}

We used the rat knee joint incapacitation test, as described previously, as one of the measures of the inflammatory joint hypernociception [9]. Briefly, after 
zymosan injection, rats were put to walk on a steel rotary drum $(30 \mathrm{~cm}$ wide $\times 50 \mathrm{~cm}$ diameter $)$ that rotates at $3 \mathrm{rpm}$. Specially designed metal gaiters were wrapped around both hind paws. After placement of the gaiters, the animals were allowed to walk freely for habituation. The right paw was then connected via a simple circuit to a microcomputer data input/output port. The paw elevation time (PET) is the time for which, over a 60-s period, the inflamed hind paw is not in contact with the cylinder. This is directly proportional to the articular incapacitation. The PET was measured at baseline and then hourly, until killing, at $6 \mathrm{~h}$. Results (s/1 min) are reported as the maximal PET that occurs between 3 and $4 \mathrm{~h}$ after injection of the zymosan.

For evaluation of joint hypernociception by the electronic von Frey method, rats were placed in acrylic cages $(12 \times 10 \times 17 \mathrm{~cm}$ high $)$ with a wire grid floor 20-30 min before testing. During this adaptation period, the paws were poked two to three times. Before right paw stimulation, the animals were quiet, without exploratory movements or defecation and not resting on their paws. In these experiments, we used a pressure-meter which consisted of a handheld force transducer fitted with a $0.5-\mathrm{mm}^{2}$ polypropylene tip (Electronic von Frey anesthesiometer, Insight Equipamentos Científicos Ltda., Ribeirão Preto, SP, Brasil). The investigator, blinded to the treatment protocol (see below), was trained to apply the polypropylene tip perpendicularly to the central area of the hind paw with a gradual increase in pressure. The test consisted of poking the right hind paw to provoke a flexion reflex followed by a clear flinch response after paw withdrawal. In the electronic pressure-meter test, the intensity of the stimulus was automatically recorded when the paw was withdrawn. The stimulation of the paw was repeated until the animal presented three similar measurements. Results are expressed as the mean of the mechanical threshold $(\mathrm{g})$ after three stimulations (pokes) at each time-point [12].

Collection of Synovial Exudates and Analysis of Cell Influx, Cytokines, and Nitric Oxide (NO) Levels in the Joint Exudates

At $6 \mathrm{~h}$ (acute phase) or 7 days (chronic phase) after injection of the zymosan, the animals were anesthetized with chloral hydrate $(400 \mathrm{mg} / \mathrm{kg}$ intraperitoneal-i.p.), killed by cervical dislocation, and exsanguinated. The synovial cavity of the knee joints was then washed twice with $0.2 \mathrm{ml}$ (rats) or $0.05 \mathrm{ml}$ (mice) of saline containing $10 \mathrm{mM}$ EDTA. The synovial exudates were collected by aspiration, and total cell counts were performed using a Neubauer chamber. After centrifugation (500 $\mathrm{g} / 10 \mathrm{~min}$ ), the supernatants were stored at $-80{ }^{\circ} \mathrm{C}$ and used for the determination of cytokine release. The concentrations of tumor necrosis factor (TNF)- $\alpha$, interleukin (IL)-1 $\beta$, IL-10, IL-17, and $\gamma$-interferon $(\gamma$-IFN) were measured in the synovial exudates obtained $6 \mathrm{~h}$ after zymosan injection in rats and mice, using a commercially available ELISA kit (R\&D Systems, São Paulo, SP, Brasil).

\section{Synovial Histopathology}

After killing, the synovia was excised, fixed in $10 \%$ buffered formaldehyde, and processed for routine hematoxylin-eosin (HE) staining. Semiquantitative histopathological grading was performed by one independent pathologist blinded to group allocation according to the presence of edema, synovial proliferation, cell infiltration, proliferation of blood vessels, fibrosis, and stage of the disease, ranging from 0 to 3 ( 0 , absent; 1 , mild; 2 , moderate; 3 , severe) for each parameter. The maximal total score was 18 . Results are expressed as the median (variation) value for each group of six animals [5].

Immunohistochemistry for Inducible Nitric Oxide Synthase (iNOS) Detection

The synovial samples were used to assess the expression of the iNOS enzyme, using a commercially available rabbit anti-NOS2 antibody (Santa Cruz Biotechnology, Santa Cruz, CA, USA). Briefly, after deparaffinization, the tissues were incubated with hydrogen peroxide and washed. After incubation in citrate buffer, specimens were subjected to slight heating in a microwave oven. After overnight unspecific blocking with rabbit serum, the samples were incubated with the rabbit anti-NOS2 antibody (diluted 1:200 in PBS plus $1 \%$ of BSA, 2 h). After rinsing, the sections were incubated with a secondary biotinylated anti-rabbit IgG antibody. The reaction product was detected using Envision ${ }^{\mathrm{TM}}$ System-HRP (AEC) 
complex (DAKO, Carpinteria, CA, USA), and the color of the reaction was developed with diaminobenzidine tetrahydrochloride (DAKO, Carpinteria, CA, USA). The slides were counterstained with Mayer's hematoxylin. The intensity of the staining was analyzed under light microscopy, by counting the number of positive cells/10 randomly selected fields, and was scored as follows: $0=$ no staining; $1=$ lowintensity staining in $<50 \%$ of the cells; $2=$ intense staining in $<50 \%$ of the cells; and $3=$ intense staining in $>50 \%$ of the cells. Results are expressed as the median (variation) value for each group of six animals.

Evaluation of Cell Death In Vivo

We used the ApopTag Plus Peroxidase In Situ Detection Kit (Serologicals Corp., Norcross, GA, USA) for TUNEL (terminal deoxynucleotidyltransferasemediated dUTP-biotin nick end labeling) in order to detect apoptosis in the synovial specimens. The ApopTag Plus Peroxidase In Situ Detection Kit distinguishes apoptosis from necrosis by specifically detecting DNA cleavage and chromatin condensation associated with apoptosis. However, cells that morphologically appear to be necrotic may stain lightly. In addition, DNA fragmentation can be absent or incomplete in induced apoptosis. Therefore, the results were presented as TUNEL-positive cells [13]. Paraffin-embedded synovial sample sections were hydrated and incubated with $20 \mu \mathrm{g} / \mathrm{ml}$ of proteinase $\mathrm{K}$ (Sigma, Brasil) for $15 \mathrm{~min}$ at room temperature (RT). Endogenous peroxidase was blocked by treatment with $3 \%$ (wt/vol) hydrogen peroxide in PBS for $5 \mathrm{~min}$ at RT. Slides were then washed with PBS, and sections were incubated in a humidified chamber at $37{ }^{\circ} \mathrm{C}$ for $1 \mathrm{~h}$ with TdT buffer containing TdT enzyme and reaction buffer. Samples were then incubated for $10 \mathrm{~min}$ at RT with a stop/wash buffer and then incubated in a humidified chamber for $30 \mathrm{~min}$ with anti-digoxigenin-peroxidase conjugate at RT. Following washing several times in PBS, the slides were covered with peroxidase substrate to develop color and then washed in three changes of distilled $\mathrm{H}_{2} \mathrm{O}$ and counterstained in $0.5 \%$ ( $\mathrm{vol} / \mathrm{vol})$ methyl green for $10 \mathrm{~min}$ at RT. Cell apoptosis was measured by counting the number of TUNEL-positive cells in 10 randomly selected fields from each sample, under light microscopy. Thus, TUNEL-positive cells represent apoptotic cells and possibly some necrotic cells. Data are presented as mean \pm s.e.m. of stained cells/group.

\section{Assessment of Articular Cartilage Damage}

The glycosaminoglycan (GAG) content of the articular cartilage was determined as follows: The cartilage of the distal femoral extremities was excised. The samples were weighed after drying overnight at $80{ }^{\circ} \mathrm{C}$. The material was subjected to proteolysis using Prolav 750 (Prozyn, São Paulo, SP, Brasil) and further precipitation in absolute ethanol, followed by dilution in distilled water. This material was separated on a $0.6 \%$ agarose gel electrophoresis. After staining with $0.1 \%$ toluidine blue, quantitation was made by densitometry $(525 \mathrm{~nm})$. For comparison, standards of chondroitin 4-sulfate and chondroitin 6-sulfate were subjected to the same protocol. Data were expressed as $\mu \mathrm{g} \mathrm{GAG/mg} \mathrm{of} \mathrm{dried} \mathrm{cartilage} \mathrm{[14].}$

\section{Preparation of the $C$. posadasii Extract}

The antigenic extract was prepared with a $C$. posadasii strain (CEMM 01-6-085) isolated in Ceará State (Brazil) from a clinical source. The isolate belongs to the Specialized Medical Mycology Center (CEMM) culture collection and was identified by mycological analysis. In brief, cultures of the mycelia phase were grown in a $2 \%$ glucose $/ 1 \%$ yeast extract broth for approximately 30 days at $30{ }^{\circ} \mathrm{C}$. Each culture was killed with $0.2 \mathrm{~g}$ thimerosal/l (ethylmercurithiosalicylic acid sodium salt; Synth, São Paulo, SP, Brasil), and the supernatant was collected by paper filtration. Protein was precipitated with solid ammonium sulfate (Sigma-Aldrich, São Paulo, SP, Brasil) until the filtrate reached $90 \%$ saturation. The mixture was kept at $4{ }^{\circ} \mathrm{C}$ for $24 \mathrm{~h}$, and then the precipitated proteins were recovered by centrifugation and dialysed exhaustively against a $10 \times$ volume of distilled water using a dialysis membrane with a $10 \mathrm{kD}$ molecular mass cutoff [15]. As a separate step to denature proteins present in the extract, a sample of the dialysate was subjected to a reducing process, by incubating with $45 \mathrm{mM}$ dithiothreitol (DTT) for $1 \mathrm{~h}$, at $56{ }^{\circ} \mathrm{C}$, followed by alkylation with $100 \mathrm{mM}$ iodoacetamide for $3 \mathrm{~h}$, at room temperature. The dialysates were stored at $-20{ }^{\circ} \mathrm{C}$ until use [16]. 
Characterization of Components in the

C. posadasii Extract

As an initial attempt to identify proteins present in the $C$. posadasii extract, it was run on a silverstained polyacrylamide gel (12\%) electrophoresis in glycine buffer. The presence of charged carbohydrates was investigated by separating the $C$. posadasii extract in a $6 \%(\mathrm{wt} / \mathrm{vol})$ polyacrylamide gel electrophoresis in diaminopropane acetate buffer (50 mM [pH 9.0]). This gel was stained with a $0.1 \%(\mathrm{wt} / \mathrm{vol})$ toluidine blue solution. For comparison, high- and low-molecular-weight standards (Bio-rad, São Paulo, SP, Brasil) as well as standard chondroitin 4-sulfate and chondroitin 6-sulfate (Sigma, St. Louis, MO, USA) were subjected to the same protocols, as indicated.

\section{Treatments}

Test groups received the $C$. posadasii extract, dissolved in sterile saline, either i.p. or per os (p.o.) 30 min prior to the i.a. injection of zymosan. The amount of extract to be administered was based on protein content, using the Bradford method [17]. After obtaining a dose-response curve $(10-100 \mu \mathrm{g})$ in mice or rats, groups of animals received the reduced/ alkylated extract in order to test for the activity of protein components, as follows: To reduce disulfide bonds, $100 \mathrm{mM}$ DTT was added to a final concentration of $10 \mathrm{mM}$ in the protein solutions and incubated for $1 \mathrm{~h}$ at $56{ }^{\circ} \mathrm{C}$ in the dark. Free thiol (-SH) groups were subsequently alkylated with iodoacetamide (50 mM final concentration) for $45 \mathrm{~min}$ at room temperature. In order to rule out the effect of an irrelevant protein, a group of animals subjected to ZYA received $100 \mu \mathrm{g}$ bovine serum albumin (BSA), either i.p. or p.o.

\section{Statistical Analysis}

Data are presented as mean \pm standard error of the mean (SEM) or medians (range), as appropriate. Differences between means and medians were analyzed using one-way analysis of variance followed by Tukey's test or Kruskal-Wallis test, respectively. $p<0.05$ was considered significant.

\section{Results}

Coccidioides posadasii Extract Reduced Cell

Influx in acute and chronic ZYA in Rats and Mice

Administration of zymosan into the joints of rats and mice induced cell influx into the joint cavity that was most intense at $6 \mathrm{~h}$, with predominance $(>85 \%)$ of polymorphonuclear cells. At 7 days, cell counts in joint exudates were less pronounced, with mononuclear cells being predominant [9]. Figure 1 shows that administration of the C. posadasii extract, either i.p. or p.o., significantly and dose dependently reduced cell influx in the acute and chronic phase of ZYA in both species, as compared to vehicle-treated animals. Moreover, the isolated administration of the C. posadasii extract to naive animals did not alter cell counts. In order to exclude endotoxin contamination, we should stress that both the extract and BSA solution were prepared under sterile conditions and filtered before administration. Additionally, incubation of C. posadasii extract with polymyxin did not modify its effects on acute cell influx (data not shown). Also, the fact that the extract was effective after being given orally per se excludes the possibility of endotoxin contamination as responsible for the effects observed. In an attempt to demonstrate that a protein component is responsible for the effect observed with the C. posadasii extract, we subjected the extract to a reducing/alkylating process, a step that denatures proteins containing disulfide bridges. As shown in Fig. 1e, administration of the extract following this protein-denaturing process led to a significant reduction in the effect observed with the crude extract. The administration of a $100 \mu \mathrm{g}$ BSA solution given as an irrelevant protein either p.o. or i.p. did not alter hypernociception or cell influx (data not shown).

\section{Coccidioides posadasii Extract Reduced Hypernociception in ZYA in Rats}

Rats subjected to ZYA displayed an intense hypernociceptive response measured using both the articular incapacitation test and the von Frey methods, as shown in Fig. 2a, b, respectively. Similar to what happened with the cell influx, pretreatment of the animals with the C. posadasii extract, regardless of using i.p. and p.o. routes, significantly reduced the acute hypernociception measured with the articular incapacitation test (Fig. 2a) 

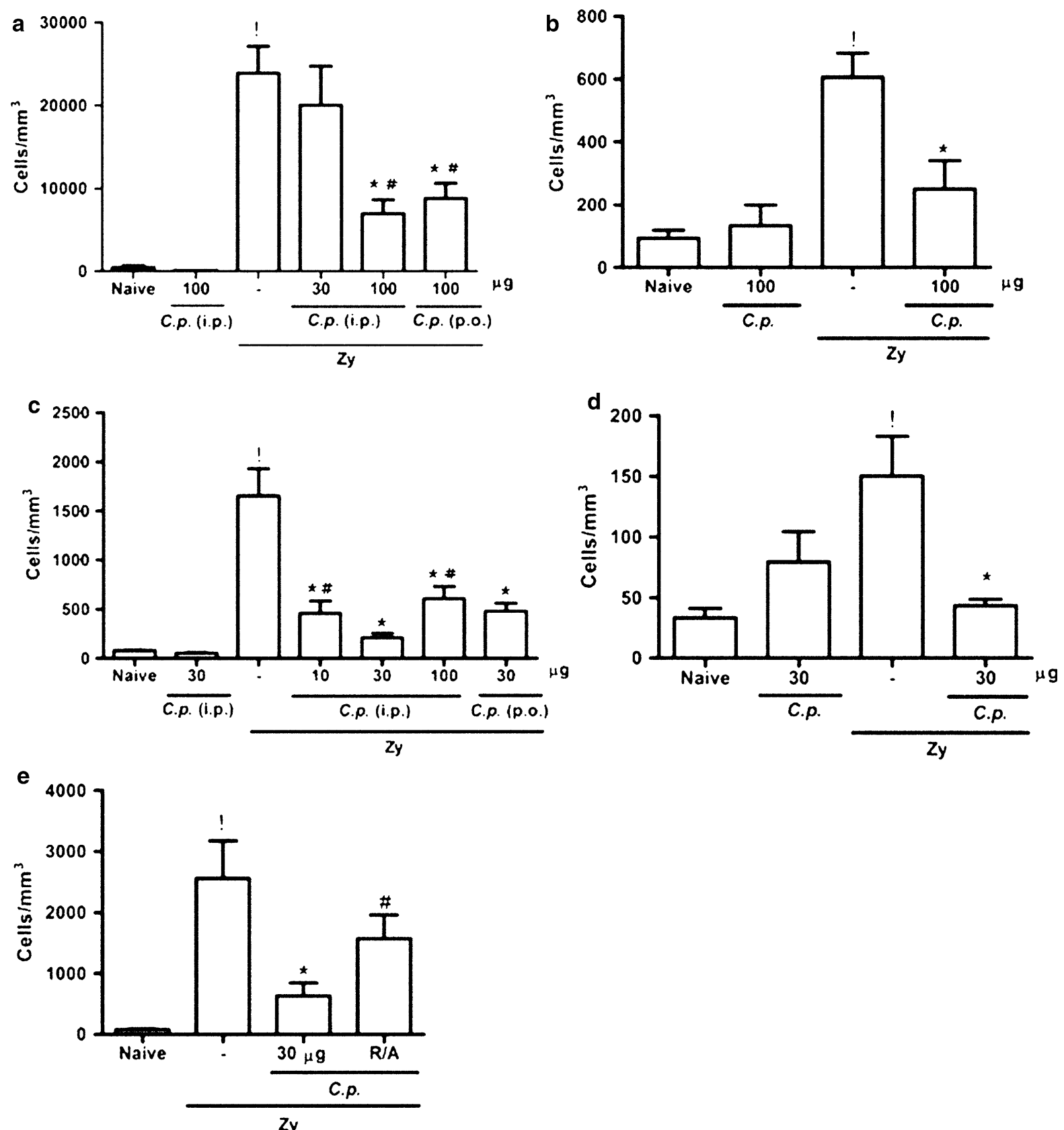

Fig. 1 Effect of the parenteral and oral administration of the C. posadasii (C.p.) extract on the cell influx in acute and chronic zymosan-induced arthritis (ZYA) in rats and mice. Rats $(\mathbf{a}, \mathbf{b})$ and mice $(\mathbf{c}, \mathbf{d}, \mathbf{e})$ received the C.p. extract or saline (-) either i.p. or p.o. $30 \mathrm{~min}$ prior to $1 \mathrm{mg}$ or $0.1 \mathrm{mg}$ zymosan i.a., respectively. (e) Mice received the reduced/alkylated C.p. extract (R/A) i.p. $30 \mathrm{~min}$ prior to $0.1 \mathrm{mg}$ zymosan i.a.

as well as the persistent chronic hypernociceptive response measured from $3 \mathrm{~h}$ until 7 days after injection of the zymosan, using the electronic von Frey method

Naive rats or mice received saline i.a. or saline i.a. plus C.p. extract i.p. Cell infiltration into joint cavities was assessed $6 \mathrm{~h}(\mathbf{a}, \mathbf{c}, \mathbf{e})$ or 7 days $(\mathbf{b}, \mathbf{d})$ after injection of zymosan. Results show mean \pm SEM of total leukocytes $(n=6$ animals for each group); : $p<0.05$ compared to naive; $* p<0.05$ compared to control (-) rats and mice; ${ }^{\#} p<0.05$ compared to C.p. $30 \mu \mathrm{g}$

(Fig. 2b), as compared to vehicle-treated animals. Administration of the $C$. posadasii extract to naive animals did not alter the hypernociceptive response. 

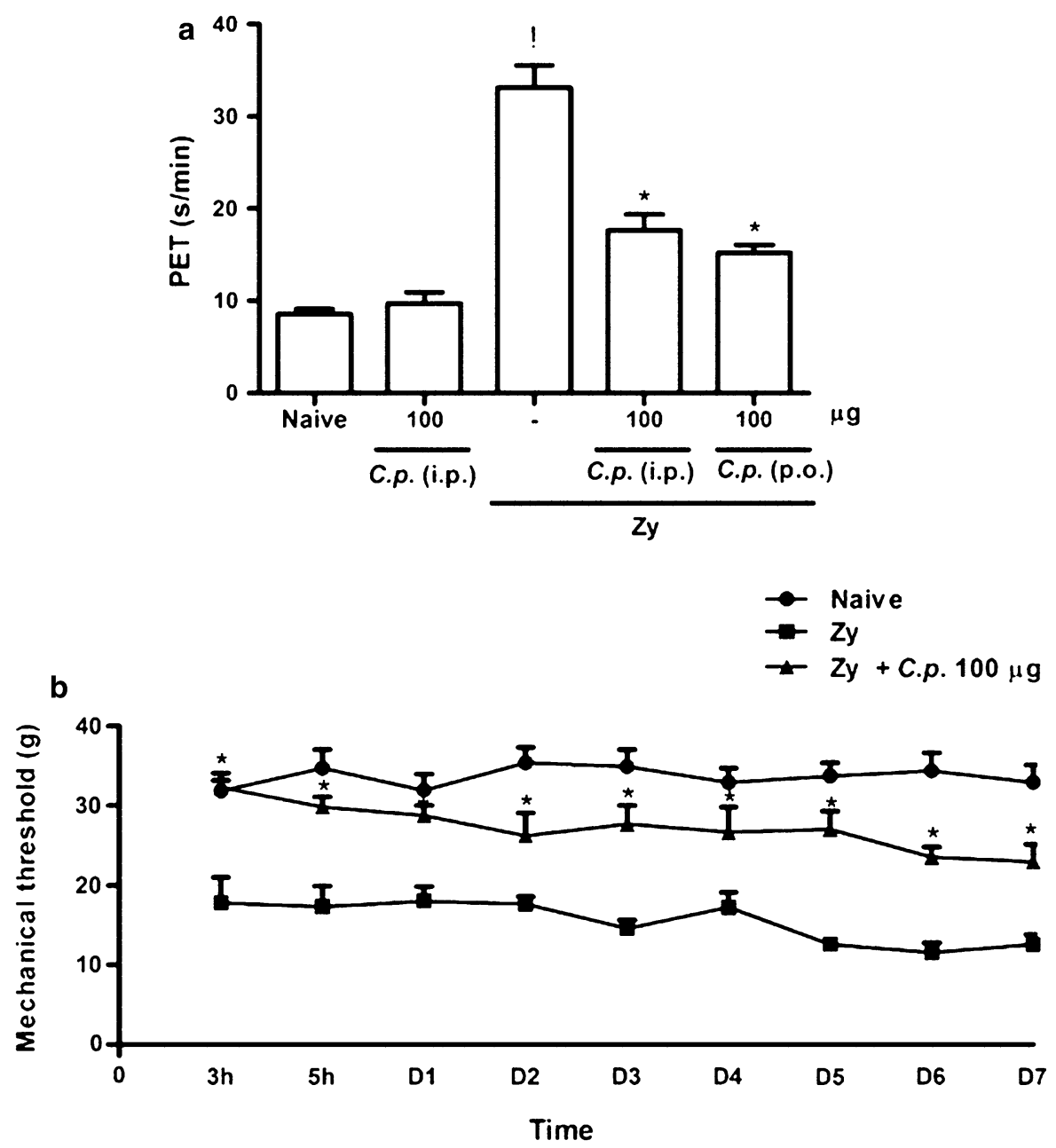

Fig. 2 Effect of the parenteral and oral administration of the C.p. extract on the hypernociception in acute (a) or chronic (b) ZYA in rats. a Rats received the C.p. extract or saline (-) either i.p. or p.o. $30 \mathrm{~min}$ prior to $1 \mathrm{mg}$ zymosan. Naive rats received saline i.a. Articular incapacitation was measured hourly over $4 \mathrm{~h}$ as the increase in PET using the rat knee joint incapacitation test. Results show mean \pm SEM of maximal PET between 3 and 4 h of arthritis. $n=6$ animals for each group;

\section{Coccidioides posadasii Extract Effect on Cartilage Damage in ZYA in Rats}

The GAG loss in the articular cartilage measured after 7 days of ZYA can be used as an index of structural joint damage in this model. As compared to naive animals, those that received i.a. zymosan displayed a significant reduction in the GAG content [18]. The administration of the C. posadasii extract provoked a partial, though not reaching statistical significance, reversion of the decrease in the GAG content of the cartilage, as
! $p<0.05$ compared to naive rats; $* p<0.05$ compared to control (-) rats. b Rats received the C.p. extract or saline (Zy) i.p. $30 \mathrm{~min}$ prior to $1 \mathrm{mg}$ zymosan. Naive rats received saline i.a. The flexion-elicited hypernociception withdrawal threshold (g) was evaluated 3, $5 \mathrm{~h}$, and then daily for 7 days after injection of the zymosan. Results show mean \pm SEM of nociceptive threshold; $n=6$ animals for each group. ${ }^{*} p<0.05$ compared to control (Zy) rats

compared to vehicle-treated rats, as follows: naive (44.1 $\pm 7.05 \mu \mathrm{g} / \mathrm{mg})$; zymosan $(31.2 \pm 4.92 \mu \mathrm{g} / \mathrm{mg})$; and $C$. posadasii + zymosan $(36.7 \pm 3.65 \mu \mathrm{g} / \mathrm{mg})$.

\section{Coccidioides posadasii Extract Reduced} the Histopathology Changes of the Synovia in ZYA in Mice

Figure 3 illustrates the histopathological appearance of the synovia of mice subjected to ZYA. It can be seen that pretreatment with the $C$. posadasii extract (Fig. 3c) 

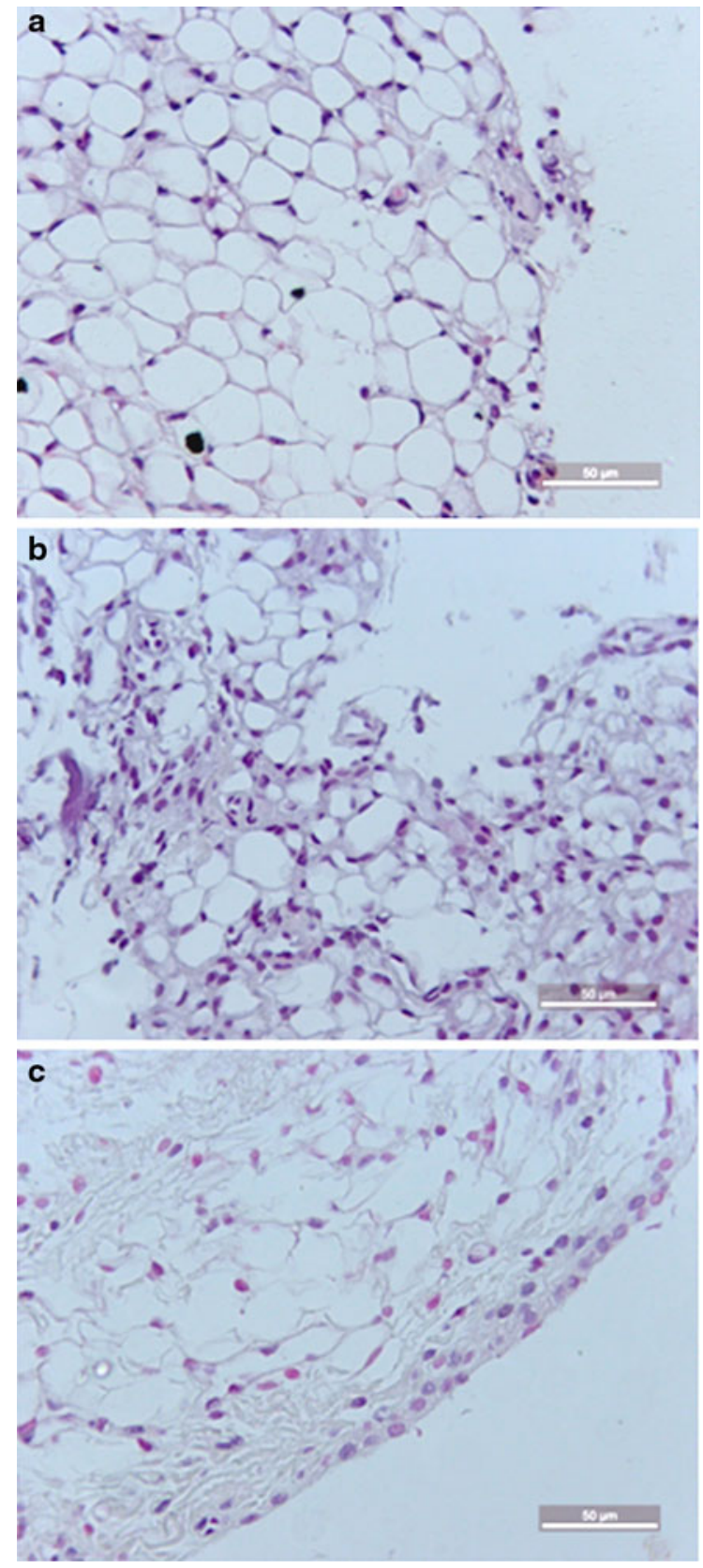

Fig. 3 Representative illustration of the synovial histopathology of mice subjected to ZYA and treated with the C.p. extract. Mice received $30 \mu \mathrm{g}$ of C.p. extract (c) or saline (b) given i.p. $30 \mathrm{~min}$ prior to $0.1 \mathrm{mg}$ zymosan i.a. Naive mice (a) received saline i.a. All animals were killed at 7 days. The synovia of animals that received just the zymosan displays intense and diffuse mononuclear cell infiltration (b) that is clearly reduced in the mice that received the C.p. extract prior to zymosan (c). $\mathrm{H}$ \& $\mathrm{E}$ staining. (Original magnification $\times 400$ ) almost completely abrogated the synovitis, provoking a marked decrease in the number of infiltrating cells. A synovial sample of a naive mouse is shown for comparison (Fig. 3a), as well as the sample from an animal subjected to ZYA treated with the vehicle (Fig. 3b). The administration of the extract also provoked a decrease in synovial cell hyperplasia, neovascular formation, and fibrosis, as shown in Table 1.

\section{Coccidioides posadasii Extract Reduces Cell Death in the Synovial Layer}

Injection of the zymosan significantly increased the number of TUNEL-positive cells (apoptosis and possibly necrosis) as compared to synovial samples from naive animals, which display no staining (Fig. 4). The number of TUNEL-positive cells was significantly reduced in the samples from the animals that were treated with the $C$. posadasii extract, as compared to those that received zymosan and the vehicle (cell death is indicated by the brown staining of the cells detected by the TUNEL method).

\section{Coccidioides posadasii Extract Decreases iNOS Activation in the Synovia}

Figure 5a-c illustrates photomicrographs of the immunostaining for iNOS activity in the synovia obtained from negative control (5a), naive (5b), zymosan (5c), and $30 \mu \mathrm{g}$ C.p. + zymosan (5d) groups. There is a clear and significant $(p<0.02)$ reduction in the immunostaining in the samples of animals that received C.p. extract (median score $=1$; range 0-2), as compared to those that received zymosan and the vehicle (median score $=2$; range $1-3)$.

Effect of the C. posadasii Extract on the Release of Inflammatory Mediators in acute ZYA

The $C$. posadasii extract did not alter the release of IL-1 $\beta$, TNF- $\alpha, \gamma$-IFN, and IL-17 into the joints of mice subjected to ZYA (Fig. 6a, b, c, d, respectively). The levels of these cytokines were measured at $6 \mathrm{~h}$ of arthritis in the joint exudates. On the other hand, Fig. 6e shows that IL-10 joint levels, also measured at $6 \mathrm{~h}$, were significantly reduced, as compared to salinetreated animals. 
Table 1 Effect of the C. posadasii extract on joint damage by histopathology in ZYA

\begin{tabular}{|c|c|c|c|c|c|c|c|}
\hline Group & $\begin{array}{l}\text { Cell } \\
\text { infiltration }\end{array}$ & $\begin{array}{l}\text { Stage of the } \\
\text { disease }\end{array}$ & $\begin{array}{l}\text { Synovial } \\
\text { proliferation }\end{array}$ & $\begin{array}{l}\text { Proliferation of blood } \\
\text { vessels }\end{array}$ & Fibrosis & Edema & $\begin{array}{l}\text { Scores } \\
\text { total }\end{array}$ \\
\hline Naive & $\begin{array}{l}0 \\
(0-1.0)\end{array}$ & $\begin{array}{l}0 \\
(0-1.0)\end{array}$ & $\begin{array}{l}0 \\
(0-1.0)\end{array}$ & $\begin{array}{l}0 \\
(0-1.0)\end{array}$ & $\begin{array}{l}0 \\
(0-0)\end{array}$ & $\begin{array}{l}0 \\
(0-0)\end{array}$ & $\begin{array}{l}0 \\
(0-2.0)\end{array}$ \\
\hline $\mathrm{Zy}$ & $\begin{array}{l}2.0 \\
(1.0-3.0)\end{array}$ & $\begin{array}{l}2.0 \\
(1.0-2.0)\end{array}$ & $\begin{array}{l}1.0 \\
(0-3.0)\end{array}$ & $\begin{array}{l}1.0 \\
(1.0-2.0)\end{array}$ & $\begin{array}{l}2.0 \\
(1.0-2.0)\end{array}$ & $\begin{array}{l}1.0 \\
(0-2.0)\end{array}$ & $\begin{array}{l}9.5 \\
(6.0-13.0)\end{array}$ \\
\hline $\mathrm{Zy}+C \cdot p$. & $\begin{array}{l}0 * \\
(0-1.0)\end{array}$ & $\begin{array}{l}1.0 * \\
(0-2.0)\end{array}$ & $\begin{array}{l}0 * \\
(0-1.0)\end{array}$ & $\begin{array}{l}0 * \\
(0-1.0)\end{array}$ & $\begin{array}{l}0 * \\
(0-2.0)\end{array}$ & $\begin{array}{l}1.0 \\
(0-2.0)\end{array}$ & $\begin{array}{l}3.0 * \\
(0-8.0)\end{array}$ \\
\hline $\mathrm{R} / \mathrm{A}$ & $\begin{array}{l}2.0 \\
(2.0-3.0)\end{array}$ & $\begin{array}{l}2.5 \\
(2.0-3.0)\end{array}$ & $\begin{array}{l}1.5 \\
(0-2.0)\end{array}$ & $\begin{array}{l}1.0 \\
(1.0-1.0)\end{array}$ & $\begin{array}{l}0.5 * \\
(0-1.0)\end{array}$ & $\begin{array}{l}0.5 \\
(0-1.0)\end{array}$ & $\begin{array}{l}8.0 \\
(7.0-9.0)\end{array}$ \\
\hline
\end{tabular}

Mice received $30 \mu \mathrm{g}$ of C.p. extract $(\mathrm{Zy}+$ C.p.), a reduced/alkylated (R/A) C.p. extract or saline given i.p. (Zy), $30 \mathrm{~min}$ prior to $0.1 \mathrm{mg}$ zymosan i.a. Naive mice received saline i.a. All animals were killed at 7 days. Results represent medians of synovial histopathology scores

$* p<0.05$ compared to control (Zy) mice ( $n=6$ animals for each group)

Analogous to what was observed in mice, the C. posadasii extract did not alter the release of IL-1 $\beta$ and TNF- $\alpha$ into the joints of rats subjected to ZYA (Fig. 7a, b, respectively). The levels of these cytokines were measured at $6 \mathrm{~h}$ of arthritis in the joint exudates. On the other hand, Fig. 7c shows that IL10 joint levels, also measured at $6 \mathrm{~h}$, were significantly reduced, as compared to saline-treated animals.

Preliminary Characterization of Components in the C. posadasii Extract

Figure $8 \mathrm{a}, \mathrm{b}$ illustrates a silver-stained $12 \%$ polyacrylamide electrophoresis gel of the $C$. posadasii extract to identify proteins and a toluidine blue-stained $6 \%$ agarose gel electrophoresis aimed to identify charged carbohydrates, respectively. Analysis of the proteins run on lane 2 was done using E-Capt ${ }^{\mathrm{TM}}(12.7$ version for Windows) software aiming to estimate the molecular weight comparing to the Bio-rad ${ }^{\mathrm{TM}}$ standards run on parallel. Twelve bands were identified, ranging from 4 to $172 \mathrm{kD}$. There is a wide range of both low- and high-molecular-weight proteins shown in the silver-stained gel. Additional purification is needed in order to try to identify active components implicated in the protective effects of the $C$. posadasii extract. On the other hand, the absence of charged carbohydrates, as shown on lane 3 of Fig. 8b, virtually excludes such components as responsible for the results achieved.

\section{Discussion}

The present study demonstrates that a $C$. posadasii extract, administered either parenterally or per os, has dose-dependent in vivo anti-inflammatory properties by inhibiting joint hypernociception and acute neutrophil migration into the inflamed joints as well as the increase in mononuclear cell counts in the chronic phase - 7 days — of zymosan arthritis. At histopathology, neovascular formation, fibrosis, lymphocyte, and mononuclear cell proliferation together with hyperplasia of the synovial lining cells were also significantly reduced by the pre-administration of a single dose of the $C$. posadasii extract. In keeping with the pathogenetic relevance of the present results, joint damage, assessed by measuring the glycosaminoglycan content of the cartilage, was reduced, though not significantly, in animals that received the fungal extract, as compared to vehicle-treated rats. The demonstration of efficacy in different species, dose dependence, and activity in the acute and chronic phases both orally and parenterally clearly adds to the bulk of important anti-inflammatory and immunomodulating properties described with other fungal products [19].

Synovial resident cells, macrophages, and neutrophils present in the inflamed synovia are main sources of reactive oxygen species during synovitis. Zymosaninduced arthritis is characterized by an acute influx of polymorphonuclear cells that is more prominent at $6 \mathrm{~h}$, while mononuclear cells (mostly lymphocytes 
a
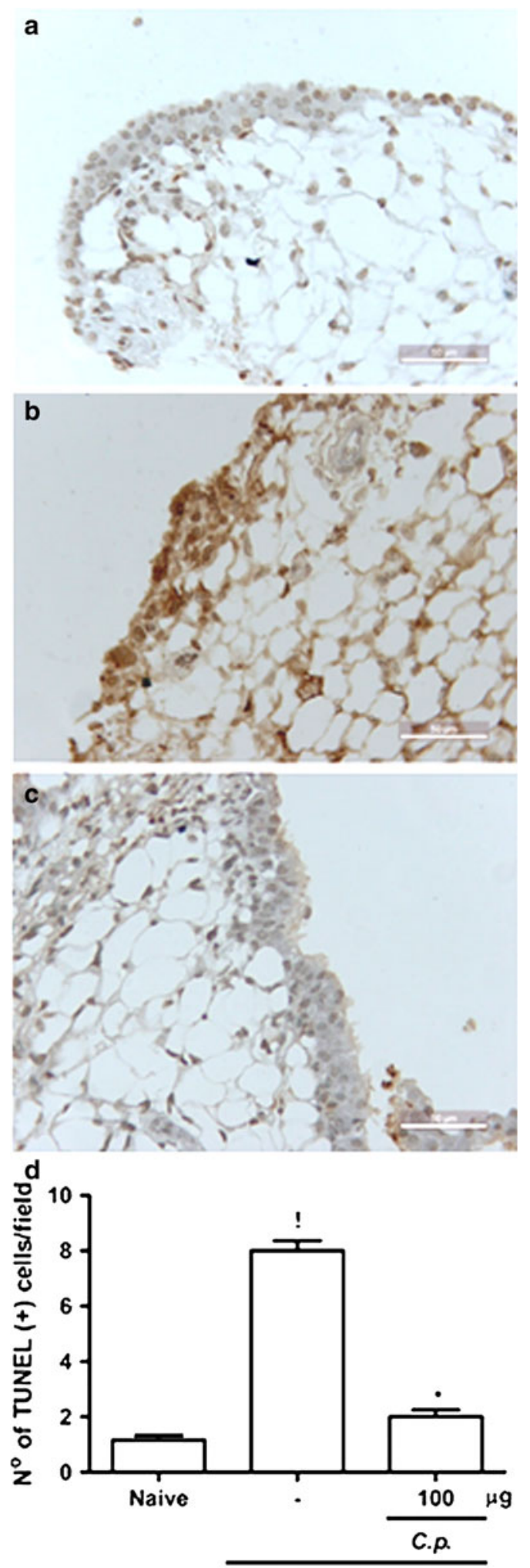

Zy
4Fig. 4 Representative illustration of the effect of C.p. extract on cell death in the zymosan-inflamed synovial detected by TUNEL method. Mice received $30 \mu \mathrm{g}$ of C.p. extract (c) or saline (b) given i.p. $30 \mathrm{~min}$ prior to $0.1 \mathrm{mg}$ zymosan i.a. Naive mice (a) received saline i.a. All animals were killed at $6 \mathrm{~h}$. The results are expressed as the average number of TUNEL-positive cells. $p<0.05$ when compared to zymosan

and monocytes) predominate after the first day. At 7 days, there is an intense chronic synovitis with synovial hyperplasia and mononuclear cell proliferation, together with angiogenesis, fibrosis, and, eventually, giant cell formation [9]. As a result, inflammatory mediators, particularly cytokines, can be directly assessed in the joint exudates, thus allowing the study of mechanisms involved in synovitis development.

We have demonstrated that neutrophils contribute to the formation of both nitric oxide (NO) and peroxynitrite in zymosan arthritis [20]. In the present study, administration of the C. posadasii extract markedly decreased the expression of iNOS in the inflamed synovia. Release of NO by macrophages has been proposed to be a protective mechanism linked to innate immunity that prevents disease development in subjects exposed to other fungi, for example, Paracoccidioides brasiliensis [21]. However, we are not aware of in vivo data showing that fungi components given systemically alter NO release either locally or systemically. Mice injected intraperitoneally with viable $C$. immitis display increased urine nitrate levels, thus reflecting augmented NO production following coccidiomycosis development [22]. On the other hand, macrophages stimulated with zymosan particles in vitro show a decreased release of NO when in the presence of $P$. brasiliensis-derived peptides [21]. Our in vivo data suggest that administration of the C. posadasii extract provoked a decrease in iNOS activation, predominantly in synoviocytes, thereby reducing the generation of reactive oxygen species in the joint.

Joint damage, pain, as well as cell infiltration observed in zymosan arthritis are closely related to the increase in the production of proinflammatory mediators such as TNF- $\alpha$ and IL-1 $\beta$ locally [23, 24]. Other cytokines, including IL-10 and IL-17, have been described to participate in the pathogenesis of fungi reactions as well as in arthritis. While the former may display anti-inflammatory properties [25], the latter has been implicated in the acute hypernociception in 


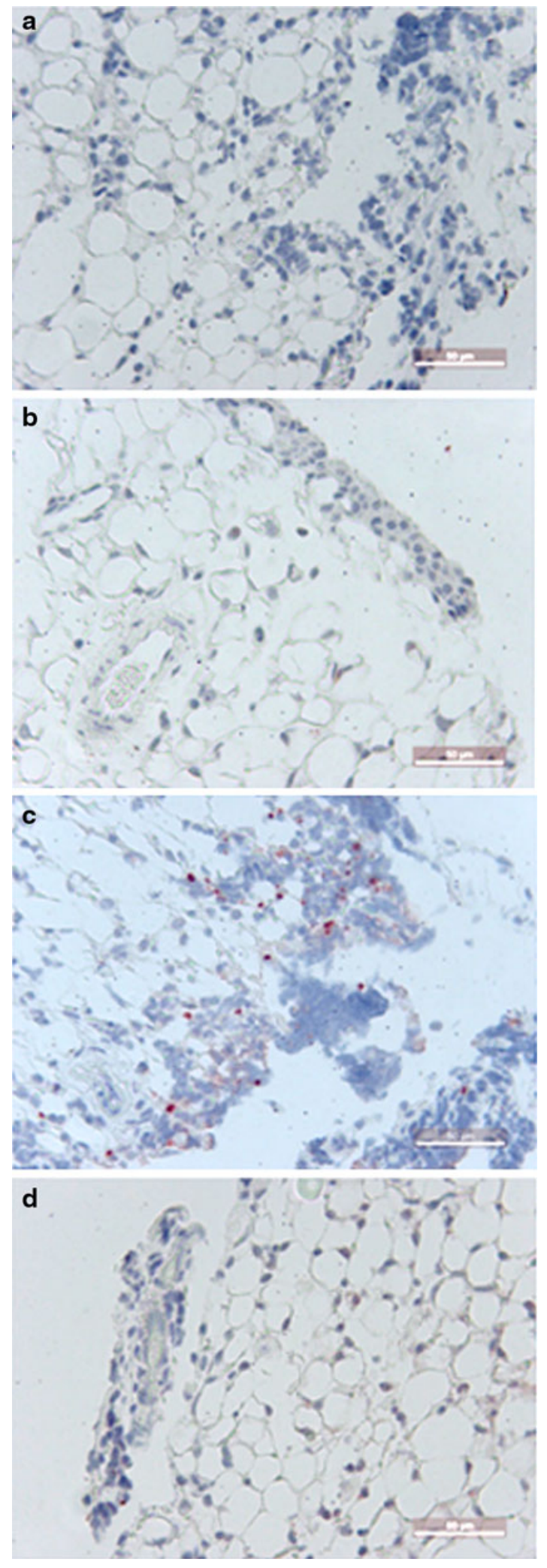

4Fig. 5 Representative illustration of the immunoexpression of iNOS in the synovia. Mice received $30 \mu \mathrm{g}$ of C.p. extract (d) or saline (c) given i.p. $30 \mathrm{~min}$ prior to $0.1 \mathrm{mg}$ zymosan i.a. Naive mice (b) received saline i.a.; negative control (a). All animals were killed at $6 \mathrm{~h}$. There is a marked reduction in iNOS staining in the group that received C.p. extract (d) as compared to the group treated with saline $(\mathbf{c})$. (Original magnification $\times 400$ )

experimental arthritis, as we have shown recently [26]. Measuring the level of these mediators in the synovial fluid rather than in serum or using ex vivo strategies may more appropriately reflect what is happening inside the joint. Our results showed no difference between the group that received the $C$. posadasii extract and control groups regarding the release of IL-1 $\beta$, TNF- $\alpha, \gamma$-IFN, and IL-17 into the joints. We have to stress that although TNF- $\alpha$ joint levels significantly rise in rats at $6 \mathrm{~h}$ of zymosan arthritis, the levels of this cytokine are not significantly elevated in mice joints, possibly due to species variation [5]. Given that the administration of the $C$. posadasii extract did not alter $\gamma$-IFN, IL- $1 \beta$, TNF- $\alpha$, and IL-17 joint levels, our data argue against a participation of Th1 cytokines as well as these proinflammatory cytokines to explain the in vivo anti-inflammatory and immunomodulatory effects of the C. posadasii extract in zymosan arthritis.

Interestingly, our results show that IL-10 levels in the joints were significantly reduced in both rats and mice that received the $C$. posadasii extract. It was shown that experimental coccidiomycosis in susceptible mice is associated with increased levels of IL-10 in the lungs. The same group later reported that in vitro stimulation of macrophages isolated from a C. immitissusceptible mouse strain led to increased production of IL-10 and reduced levels of TNF- $\alpha$, as compared to a resistant coccidiomycosis mouse strain. These effects were reduced by an antibody against Dectin-1 [22]. In summary, those data led to a proposal that genetic ablation of the Dectin-1 gene severely impairs IL-10 production [27]. To our knowledge, there are no reports showing alteration of cytokine release following systemic administration of Coccidioides sp. components. Our data add to these previous in vitro results since we measured in vivo production directly released into inflamed joints. Thus, we speculate that protein components of our C. posadasii extract, either isolated or linked to fungal polysaccharides, interfered with zymosan coupling to Dectin-1 receptors, thereby leading to decreased IL-10 production. 

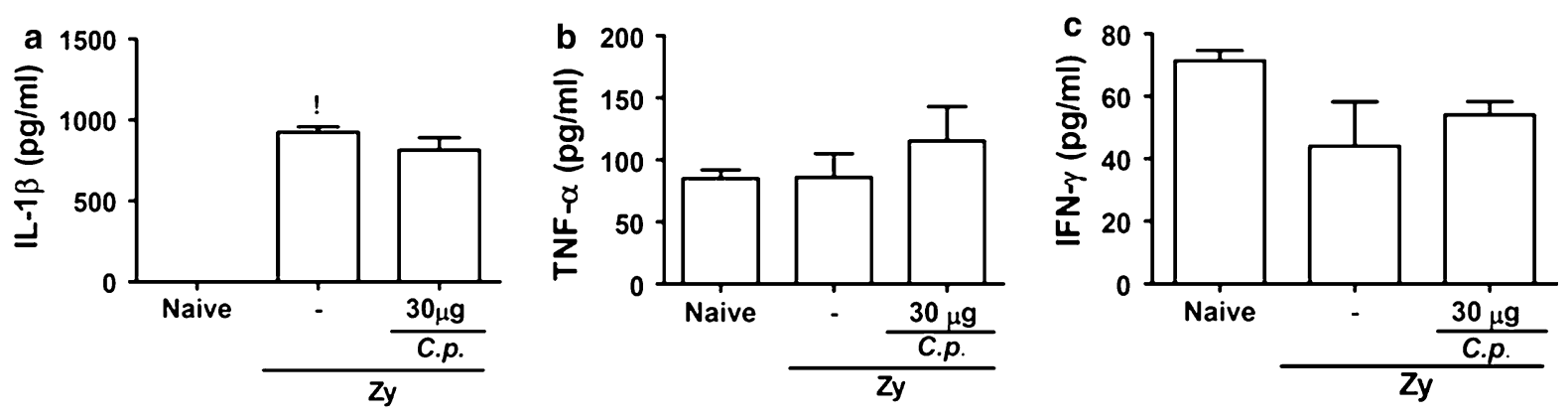

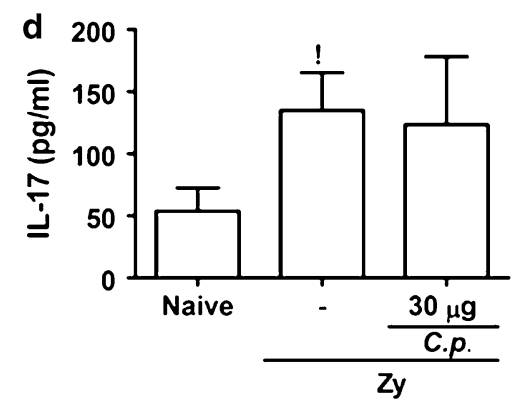

Fig. 6 Effect of the administration of C.p. extract on the release of inflammatory mediators in ZYA. Mice received $30 \mu \mathrm{g}$ of the C.p. extract or saline (-) i.p. $30 \mathrm{~min}$ prior to $0.1 \mathrm{mg}$ zymosan i.a. Naive mice received saline i.a. IL-1 $\beta$ (a), TNF- $\alpha(\mathbf{b}), \gamma$-IFN (c),

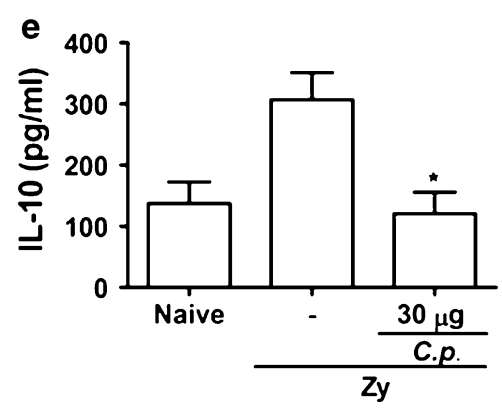

IL-17 (d), and IL-10 (e) levels were assessed using ELISA (see text for details). Results represent mean \pm SEM, measured at $6 \mathrm{~h}$ ( $n=6$ animals for each group); $p<0.05$ compared to naive mice; $* p<0.05$ compared to control $(-)$ mice
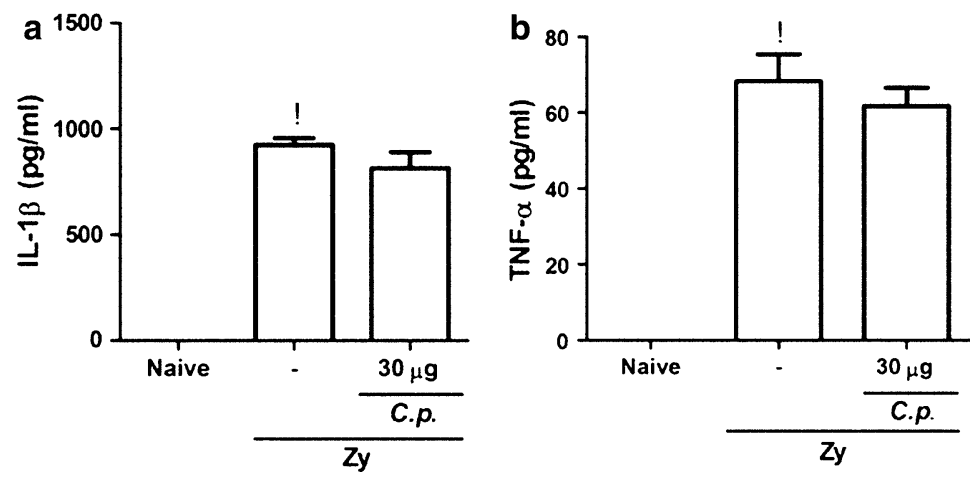

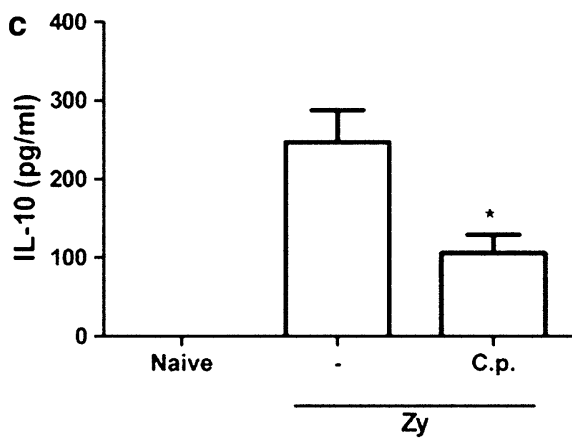

Fig. 7 Effect of the administration of C.p. extract on the release of inflammatory mediators in ZYA. Rats received $100 \mu \mathrm{g}$ of the C.p. extract or saline (-) i.p. $30 \mathrm{~min}$ prior to $0.1 \mathrm{mg}$ zymosan i.a. Naive rats received saline i.a. (a) IL-1 $\beta$, (b) TNF- $\alpha$, and

Our present results also revealed that apoptosis, predominantly of synovial lining cells, was markedly reduced in the group treated with the $C$. posadasii extract. $\mathrm{NO}$ is able to promote apoptosis of various cell types, including macrophages, neutrophils, and synoviocytes [28]. It has also been shown that stimulation of monocytederived cells with zymosan in the presence of apoptotic (c) IL-10 levels were assessed using ELISA (see text for details). Results represent mean $\pm \mathrm{SEM}$, measured at $6 \mathrm{~h} \quad(n=6$ animals for each group); $p<0.05$ compared to naive rats; $* p<0.05$ compared to control (-) rats

cells enhances IL-10 production [29]. As a possible mechanism to explain the reduced IL-10 levels promoted by the $C$. posadasii extract, we propose that the blockade of iNOS activation leads to a reduction in NO levels locally that in turn decreases the number of apoptotic cells, thus reducing IL-10 production by macrophagelike synoviocytes in the zymosan-inflamed joints. 


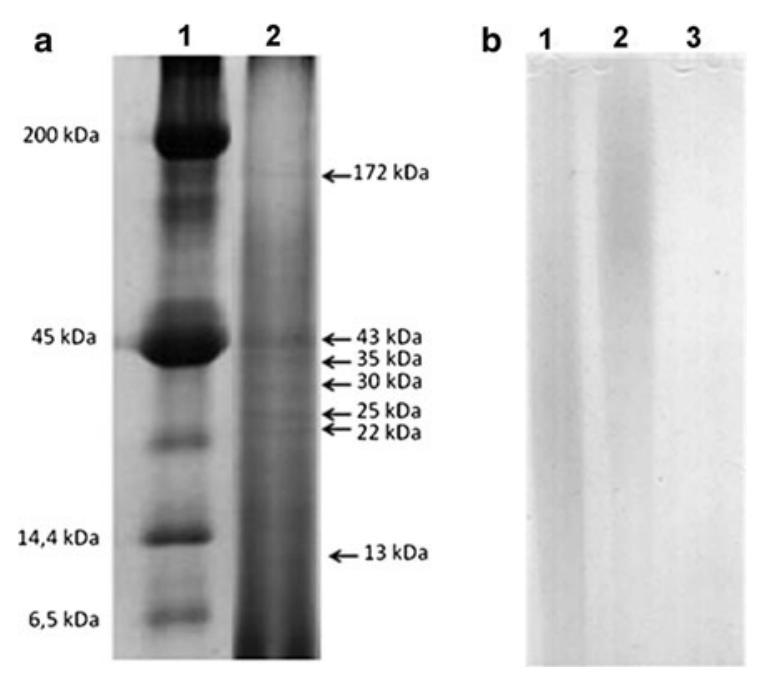

Fig. 8 Partial identification of proteins and carbohydrates present in C.p. extract. Silver-stained $12 \%$ polyacrylamide electrophoresis gel of C.p. extract (a) and a toluidine blue-stained $6 \%$ polyacrylamide electrophoresis gel for carbohydrate staining (b). a Lane 1 (Bio-rad ${ }^{\mathrm{TM}}$ standards), lane 2 $8 \mu \mathrm{g}$ C.p. extract; b Lane 1 chondroitin-4-sulfate; lane 2 chondroitin-6-sulfate; lane $38 \mu \mathrm{g}$ C.p extract

We are pursuing studies trying to isolate active component(s) present in the $C$. posadasii extract. Since the extract acted after being given orally, the possibility of lipopolysaccharide contamination to explain our data can be disregarded. The reducing/ alkylating step applied to our $C$. posadasii extract abrogated the anti-inflammatory/immunomodulating effect, thus indicating that a protein or a polypeptide containing disulfide bridges is responsible for its biological activity. We cannot exclude the possibility that isolated polysaccharides or protein/polypeptide components attached to them are responsible for the anti-inflammatory results achieved. Notwithstanding the complexity of defining a specific active component, we have to stress that our data are an in vivo original demonstration that either isolated proteins or associated with other fungi components, obtained from a dimorphic pathogenic species, are capable of modifying remote in vivo inflammatory responses. Further characterization of the specific active components in this extract that we are currently undergoing may unravel mechanistic effects that can be of relevance to understand the host response against fungal components.

Acknowledgments We thank Giuliana Bertozzi for the ELISA work. The work was partially supported by a grant from Conselho Nacional de Desenvolvimento Científico e Tecnológico (CNPq)/Fundação Cearense de Apoio ao Desenvolvimento Científico e Tecnológico (FUNCAP) (PRONEX n 2155-06) and Coordenação de Aperfeiçoamento de Pessoal de Nível Superior (CAPES), Brazil.

\section{References}

1. Lull C, Wichers HJ, Savelkoul HFJ. Antiinflammatory and immunomodulating properties of fungal metabolites. Mediators Inflamm. 2005;2:63-80.

2. Wasser SP. Medicinal mushrooms as a source of antitumor and immunomodulating polysaccharides. Appl Microbiol Biotechnol. 2002;60:258-74.

3. Bach JF. The effect of infections on susceptibility to autoimmune and allergic diseases. N Engl J Med. 2002;347: 911-20.

4. Rook GA, Stanford JL. Give us this day our daily germs. Immunol Today. 1998;19:113-6.

5. Rocha FAC, Leite AKRM, Pompeu MML, Cunha TM, Verri WA Jr, Soares FM, Castro RR, Cunha FQ. Protective effect of an extract from Ascaris suum in experimental arthritis models. Infect Immun. 2008;76:2736-45.

6. Hung CY, Xue J, Cole GT. Virulence mechanisms of Coccidioides. Ann N Y Acad Sci. 2007;1111:225-35.

7. Brass C, Levine HB, Stevens DA. Stimulation and suppression of cell-mediated immunity by endosporulation antigens of Coccidioides immitis. Infect Immun. 1982;35: 431-6.

8. Cordeiro RA, Brilhante RS, Rocha MF, Fechine MA, Camara LM, Camargo ZP, Sidrim JJ. Phenotypic characterization and ecological features of Coccidioides spp. from northeast Brazil. Med Mycol. 2006;44:631-9.

9. Rocha FAC, Aragão AGM Jr, Oliveira RC, Pompeu MML, Vale MR, Ribeiro RA. Periarthritis promotes gait disturbance in zymosan-induced arthritis in rats. Inflamm Res. 1999;48:485-90.

10. Silva FS Jr, Rocha FAC. Artrite induzida por zymosan em ratos-Mecanismos envolvidos na hipernocicepção e na lise da cartilagem articular. Acta Reum Port. 2006;31:143-9.

11. Guerrero ATG, Cunha TM, Verri WA Jr, Gazzinelli RT, Teixeira MM, Cunha FQ, Ferreira SH. Toll-like receptor 2/MyD88 signaling mediates zymosan-induced joint hypernociception in mice: participation of TNF- $\alpha$, IL-1 $\beta$ and CXCL1/KC. Eur J Pharmacol. 2012;674:51-7.

12. Guerrero ATG, Verri WA Jr, Cunha TM, Silva TA, Schivo IRS, Dal-Secco D, Canetti C, Rocha FAC, Parada CA, Cunha FQ, Ferreira SH. Involvement of $\mathrm{LTB}_{4}$ in zymosaninduced joint nociception in mice: participation of neutrophils and $\mathrm{PGE}_{2}$. J Leukoc Biol. 2008;83:122-30.

13. Kroemer G, Galluzzi L, Vandenabeele P, Abrams J, Alnemri ES, Baehrecke EH, Blagosklonny MV, El-Deiry WS, Golstein P, Green DR, Hengartner M, Knight RA, Kumar S, Lipton SA, Malorni W, Nuñez G, Peter ME, Tschopp J, Yuan J, Piacentini M, Zhivotovsky B, Melino G. Nomenclature Committee on cell death 2009. Classification of cell death: recommendations of the Nomenclature Committee on cell death 2009. Cell Death Differ. 2009;16(1):3-11.

14. Silva FS Jr, Yoshinari NH, Castro RR, Girão VCC, Pompeu MML, Feitosa JPA, Rocha FAC. Combined glucosamine 
and chondroitin sulfate provides functional and structural benefit in the anterior cruciate ligament transection model. Clin Rheumatol. 2009;28:109-17.

15. Brilhante RSN, Cordeiro RA, Rocha MFG, Fechine MAB, Furtado FM, Nagao-Dias AT, Camargo ZP, Sidrim JJC. Coccidioidal pericarditis: a rapid presumptive diagnosis by an in-house antigen confirmed by mycological and molecular methods. J Med Microbiol. 2008;57:1288-92.

16. Porto IM, Laure HJ, Tykot RH, Sousa FB, Rosa JC, Gerlach RF. Recovery and identification of mature enamel proteins in ancient teeth. Eur J Oral Sci. 2011;119:83-7.

17. Bradford MM. A rapid and sensitive method for the quantitation of microgram quantities of protein utilizing the principle of protein-dye binding. Anal Biochem. 1976;72: 248-54.

18. Bezerra MM, Brain SD, Greenacre S, Jerônimo SMB, Melo LB, Keeble J, Rocha FAC. Reactive nitrogen species scavenging, rather than nitric oxide inhibition, protects from articular cartilage damage in rat zymosan-induced arthritis. Br J Pharmacol. 2004;141:172-82.

19. Romani L. Cell mediated immunity to fungi: a reassessment. Med Mycol. 2008;46:515-29.

20. Bezerra MM, Brain SD, Girão VCC, Greenacre S, Keeble J, Rocha FAC. Neutrophils-derived peroxynitrite contributes to acute hyperalgesia and cell influx in zymosan arthritis. Naunyn Schmiedebergs Arch Pharmacol. 2007;374: 265-73.

21. Konno AYC, Maricato JT, Konno FTC, Mariano M, Lopes JD. Peptides from Paracoccidioides brasiliensis GP43 inhibit macrophage functions and inflammatory response. Microbes Infect. 2009;11:92-9.

22. del Pilar Jiménez AM, Viriyakosol S, Walls L, Datta SK, Kirkland T, Heinsbroek SEM, Brown G, Fierer J.
Susceptibility to Coccidioides species in C57BL/6 mice is associated with expression of a truncated splice variant of Dectin-1 (Clec7a). Genes Immun. 2008;9:338-48.

23. Leite ACRM, Cunha FQ, Dal-Secco D, Fukada SY, Girão VCC, Rocha FAC. Effects of nitric oxide on neutrophil influx depends on the tissue: role of leukotriene $\mathrm{B}_{4}$ and adhesion molecules. Br J Pharmacol. 2009;156:818-25.

24. Bombini G, Canetti C, Rocha FA, Cunha FQ. Tumour necrosis factor- $\alpha$ mediates neutrophil migration to the knee synovial cavity during immune inflammation. Eur J Pharmacol. 2004;496:197-204.

25. Moore KW, Malefyt RW, Coffman RL, O'Garra A. Interleukin-10 and the interleukin-10 receptor. Annu Rev Immunol. 2001;19:683-765.

26. Pinto LG, Cunha TM, Vieira SM, Lemos HP, Verri WA Jr, Cunha FQ, Ferreira SH. IL-17 mediates articular hypernociception in antigen-induced arthritis in mice. Pain. 2010;148:247-56.

27. Taylor PR, Tsoni SV, Willment JA, Dennehy KM, Rosas M, Findon H, Haynes K, Steele C, Botto M, Gordon S, Brown GD. Dectin-1 is required for b-glucan recognition and control of fungal infection. Nat Immunol. 2007;8:31-8.

28. Chen Q, Casali B, Pattacini L, Boiardi L, Salvarani C. Tumor necrosis factor-alpha protects synovial cells from nitric oxide induced apoptosis through phosphoinositide 3-kinase Akt signal transduction. J Rheumatol. 2006;33(6):1061-8.

29. Municio C, Hugo E, Alvarez Y, Alonso S, Blanco L, Fernández N. Sánchez Crespo M. Apoptotic cells enhance IL-10 and reduce IL-23 production in human dendritic cells treated with zymosan. Mol Immunol. 2011;49:97-106. 